\title{
Karl Gunnar Myrdal'ın Hayatı ve İktisadi Görüşleri
}

\section{Türker Şimşek ${ }^{1}$, Birol Çetin ${ }^{2}$}

\begin{abstract}
Özet
İktisat literatüründe söz sahibi olmuş düşünürlerin hayat hikayeleri ve fikirleri üzerine bir çok çalışma yapılmıştır. Şüphesiz Karl Gunnar Myrdal'ın iktisadi görüşleri de bundan nasibini almıştır. Ancak Myrdal'ın kişiliği ve verdiği mücadele iktisat ile ilgilenmeyen kişilerin dahi ilgisini çekmiştir. Özellikle İskandinavya ve doğu Avrupa ülkelerinde hala önemli bir ağırlığı olan Myrdal maalesef ülkemizde pek fazla tanınmamaktadır. Bu çalışma Myrdal'ın hayatı ve iktisadi görüşleri hakkında genel anlamda bilgi vermeyi amaçlamaktadır. Çalışma iki bölümden oluşmaktadır. Birinci bölümde Karl Gunnar Myrdal'ın hayatı ve eserleri, ikinci bölümde ise iktisadi görüşleri ve bazı iktisadi problemlere getirmiş olduğu çözüm önerileri ele alınmıştır.
\end{abstract}

Anahtar Kelimeler: Karl Gunnar Myrdal, Ekonomi, İsveç, Stockholm okulu

\section{Karl Gunnar Myrdal's Life and Economic Views}

\begin{abstract}
There has been made many studies about the people who became popular due to views in economic literature. No doubt the economic views of Karl Gunnar Myrdal has got its share. However, Myrdal's personality and struggle attracted the attention of even people who are not interested in economics. Myrdal has still very important weight especially in Scandinavia and Eastern European Countries but unfortunately lots of people who live in our country does not recognize Myrdal. This study is intended to provide general information about the Myrdal's life and economic views. This study consists of two chapters. In the first chapter, we deal with Karl Gunnar Myrdal's life and his works. Myrdal's economic views and the solutions of some economic problems which proposed by Myrdal are discussed in the second chapter.
\end{abstract}

Key Words: Karl Gunnar Myrdal, Economy, Sweden, Stockholm school

\footnotetext{
${ }^{1}$ Arş.Gör., Gaziosmanpaşa Üniversitesi İktisadi ve İdari Bilimler Fakültesi İktisat Böl., turker.simsek@gop.edu.tr

${ }^{2}$ Doç.Dr., Gaziosmanpaşa Üniversitesi İktisadi ve İdari Bilimler Fakültesi İktisat Böl., birol.cetin@gop.edu.tr
} 


\section{Karl Gunnar Myrdal: Hayatı ve Eserleri}

Karl Gunnar Myrdal'ın altmış yıllık kariyeri akademisyen, politikacı ve yönetici olarak Avrupa, Kuzey Amerika ve Güney Asya olmak üzere üç kıtaya; iktisat, demografi ve sosyoloji alanlarında yaptığı çalışmalarla da üç sosyal bilime yayılmıştır. Öncelikli ilgi alanı olan iktisat bilimi içerisinde iktisat teorisi, iktisat politikası ve iktisadi kalkınma gibi üç uzmanlık alanına yönelmiştir (Kindleberger, 1987: 393).

Myrdal'ın en meşhur iki eseri, 1944 yılında yazdığı 1500 sayfalık "Bir Amerikan İkilemi" ve 1968 y1lında tamamladığ 2250 sayfadan oluşan "Asya Draması " isimli kitaplardır. Myrdal, sadece iktisadi konularla ilgilenmeyip sosyal konular hakkında da görüş bildiren bir bilim adamı olduğundan; onu sadece iktisatçı olarak tanımlamak eksik olacağından, sosyal bilimci olarak tanımlamak daha doğru olacaktır. Yaşadığı dönemde yaptığı çalışmalar ile çok az kişiye nasip olan dünya çapında bir üne ulaşmayı başarabilmiştir. Amerika'da yayınlanan The New York Times gazetesi 18 Mayıs 1987 y1lında Myrdal'ın geniş biyografisine yer vermiştir. Gazete Myrdal'ı “ zamanın önde gelen ekonomist, toplum bilimci, devlet adamı, muhalif, barışsever, eşitsizlik düşmanı ve İsveç refah devletinin mimarı" olarak tanımlamıştır. Hayatı boyunca birçok onur ödülüne layık görülen Myrdal, 1974 yılında Friederich V. Hayek ile birlikte Nobel Ödülü’ne de layık görülmüştür.

Gustav Cassell, David Davidson, Eli Heckscher ve Knut Wicksell gibi ünlü İsveç ekonomistlerinden sonra Erik Lindahl, Erik Lundberg ve Bertil Ohlin ile birlikte Myrdal İsveç’in yetiştirdiği ikinci büyük ekonomistler kuşağında yer almıştır.

Gunnar Myrdal, 6 Aralık 1898 yılında İsveç'in Dalarna (eski adıyla Skattungbyn) şehrinin Solvarbo kasabasında dünyaya gelmiştir. Karl Gunnar ismini, çiftçilik yapan ve aynı zamanda tren yolu işçisi olan babası Carl Adolf Pettersson koymuştur. Karl Gunnar, hukuk eğitimi alırken kendisini arkadaşlarına Gunnar Myrdahl olarak tanıtmış ve zamanla "h" harfi kaybolarak genç hukuk öğrencisi Gunnar Myrdal olarak bilinmiştir (Myrdal J.,1982: 108).

Eğitimini aldığı Stockholm Üniversitesi'nde Knut Wicksell, David Davidson, Eli F. Heckscher ve Gustav Cassel ile birlikte çalışmıştır. Balabkins'e göre Myrdal, öğrencilik yıllarında fazla atılgan bir genç olarak göze çarpmıştır. Bir gün Gustav Cassel derste kendisini şu şekilde uyarmış: "Gunnar 
kendinden büyüklere daha saygılı bir şekilde davranmalısın. Çünkü bizler sizin gelecekteki kariyerinizi belirleyeceğiz". Myrdal'ın bu uyarı karşısındaki cevabı şöyle olmuştur: "Evet! Fakat sizler vefat ettikten sonra da bizler sizin biyografilerinizi yazacağız”. Bunlara rağmen Myrdal ve Cassel birbirlerine çok yakın davranmışlardır (Balabkins, 1988:99). 1945 yılında Cassel öldükten sonra Myrdal dediğini yapmış ve Cassel'in kısa biyografisini yazmıştır.

1924 y1lında Myrdal, Alva Reimer ${ }^{3}$ ile evlenmiş ve bu evlilikten Myrdal ailesinin üç çocuğu olmuştur: Jan, deneme yazarı ve siyaset bilimci; Sissela Ann, ahlak ve etik üzerine çalışmaları olan bir yazar (Harvard Üniversitesi rektörü Derek C. Bok'un eşi) ve; Kaj Folster ise , Gottingen'de ikamet eden bir sosyolog olarak babalarının yolunda hayatlarını şekillendirmişlerdir.. (Lindbeck, 1992).

Mayrdal 1927 y1lında doktora derecesini aldıktan sonra Stockholm Üniversitesi'nde göreve başlamıştır. 1933 ve 1939 yılları arasında politik iktisat alanında Lars Hierta ${ }^{4}$ kürsüsünde çalışmalarını sürdürmüştür. 1961 yılından 1965 y1lına kadar kendi kurmuş olduğu Ekonomi Araştırmaları Enstitüsü’nde yönetici ve uluslararası iktisat profesörü olarak çalışmıştır.

1934-1936 yıllarında İsveç Parlamentosu'nda üye, 1942-1946 yılları arasında ise Ticaret Bakanlığı görevlerinde bulunmuştur.

Mayrdal 1947 yılından 1957 y1lına kadar Birleşmiş Milletler Avrupa Ekonomi Komisyonu'nun (ECE) sekreterliğini yürütmüş, 1937 yılından 1942 yılına kadar Carnegie Corporation tarafindan An American Dilemma 'y1 yazması ve 1957 yılından 1967 y1lına kadar da Asian Drama'yı yazması için Twentieth Century Fund tarafindan desteklenmiştir. 1960'lı yılların sonlarında IndoChina'da $^{5}$ Birleşmiş Milletler Uluslararası Savaş Suçlarını Araştırma Komisyonu'nun eşbaşkanlığı, Amerikalı asker kaçakları ve firarilere yardım eden İsveç Vietnam Komitesi'nin Başkanlığı ve Stockholm Uluslararası Barış

\footnotetext{
${ }^{3}$ İsveç'teki feminist hareketin başında yer alan Alva Reimer Myrdal, kabine üyeliği, diplomatlık ve yazarlık yapmıştır. Ayrıca 1982 yılında Nobel Barış Ödülü'ne layık görülmüş̧ür (http://nobelprize.org/nobel_prizes/peace/laureates/1982/myrdal-bio.html). (http://nobelprize.org/nobel_prizes/peace/laureates/1982/myrdal-bio.html).

${ }^{4}$ Lars Johan Hierta (22 Ocak 1801 - 20 Kasım 1872) İsveçli gazete yayıncısı, sosyal eleştirmen, işadamı ve 19. yüzyılda İsveç’te politik ve sosyal reformlara yön veren ünlü bir siyasetçidir (http://www.britannica.com/EBchecked/topic/265061/Lars-JohanHierta).

${ }^{5}$ Kamboçya, Laos, Malezya, Mynamar, Singapur, Tayland ve Vietnam'ı kapsayan coğrafi bölgeye verilen isimdir.
} 
Araştırması Enstitüsü’nün Başkanlığı görevlerini başarıyla yerine getirmiştir (Kindleberger, 1987: 394).

1974 yılında Nobel Ödülü’nü aldıktan sonraki yıllarını akademik zaferin tadını çıkararak geçirmek yerine, bildiğinden vazgeçmeyerek ve sözlerini esirgemeden akademik ve sosyal hayatına devam etmiştir. Öyle ki; Nobel Ödülü'nü aldıktan sonra bile aslında bu ödülü almaması gerektiğini, çünkü bu ödülün iktisat gibi bilimsel olmayan bir alan için uygun olmadığını yazmıştır. Çoğu kişiye göre bunları yazmasındaki sebep Nobel Ödül Komitesi'nin ödülü kendisiyle, değer yargılarını paylaşmadığı Hayek arasında bölüştürmesine kızmış olmasıdır.. Burada ek bilgi olarak 1982 yılında eşi Alva Myrdal'ın Nobel Barış Ödülü’nü tek başına kimseyle paylaşmadan aldığını hatırlatmak gerekir (Pressman, 1999: 115).

Kindleberger'e göre Myrdal'1 iyi tanıyanlar egoizmi, kararlılığı, düzensizliği, enerjisini, aktifliği ve dost canlısı sıcak tavırlarından dolayı onu çalışmalarından ayırmanın ne denli zor olduğunu bilirler. 80'li yaşlarına kadar çalışmayı bırakmayan Myrdal, hayatının son yıllarını İsveç’teki evinde istirahata çekilerek geçirmiştir. Karl Gunnar Myrdal, 17 Mayıs 1987 yılında İsveç'in Danderyd şehrinde hayata gözlerini yummuştur.

\section{Myrdal'ın Genel Olarak Ekonomik Görüssleri}

Myrdal akademik yaşantısının ilk yıllarında Stockholm Okulu temsilcilerinin öne sürdüğü iktisadi analizleri benimsemiştir. Stockholm Okulu'nun benimsediği teorik yapı genellikle J.M.Keynes'in Genel Teorisi ile paralel yönde olmasına rağmen bazı önemli farklılıklar içeriyordu. Stockholm Okulu'nda yer alan iktisatçılar J.M.Keynes'in aksine bazı farklı dinamik analiz yöntemlerini dikkate almışlardır. $\mathrm{Bu}$ yöntemlerden bir tanesi de Gunnar Myrdal'ın ortaya attığı ve beklentilerin uzun dönem dengesine etki eden bağımsız bir değişken olduğunu öne sürdüğü teoridir (Myrdal, 1975).

Myrdal'ın dinamik denge yaklaşımına göre, teorik olarak dengenin belirlenmesinde beklenen bazı değişikliklerin ve hareketliliklerin sonuçları da hesaba katılmalıdır. Bu yüzden Myrdal, ekonomik analiz esnasında sadece belirleyicilerin değil aynı zamanda beklenen sonuçların veya değişim faktörlerinin de göz önünde bulundurulması gerektiğini savunmuştur. $\mathrm{Bu}$ anlayış çerçevesinde, gerçekleşmeden önce beklenen veya beklenmeyen ve uzun dönem ekonomik sürece baskı oluşturan değişikliklere dikkat etmek gerekmektedir. Myrdal bu beklenen/beklenmeyen değişikliklerin denge konusunda etkili olduğuna inanmaktadır. Çünkü fiyat oluşumu kişilerin 
kafasında şekillenmektedir. Bu yüzden dinamik teorideki denge fiyatı, statik koşuldaki denge fiyatından farklıdır. Myrdal, statik teorinin gerçeği yansıtan doğru bir yaklaşım olduğunu düşünmemektedir. Neden olarak da, statik modeldeki fiyatların gerçek fiyatlara karşılık gelmediğini söylemektedir. Ancak buna rağmen Myrdal, statik yaklaşımın daha derin ve karmaşık olan dinamik yaklaşımı anlamada, bir başlangıç olarak kullanılabileceğini ifade etmektedir (Čaplánová, 2002: 28).

Myrdal'ın parasal denge çalışmaları Knut Wicksell'in normal faiz oranları hakkındaki fikirlerine kritik bir dönüş girişimi olarak algılanmıştır. Myrdal, parasal denge çalışmasında kendisini fiyatların oluşum problemlerine ve ekonomik dalgalanmalara adayarak doktora tezinde yoğunlaşmaya devam etmiştir. Parasal dengenin teorik analizinde kullandığı ex-ante ve ex-post kavramları dinamik metodun kullanılmasında Myrdal'ın en önemli katkısı olarak kabul görmüştür. $\mathrm{Bu}$ yaklaşım, dengenin oluşamamasının açıklanmasında da kullanılmaktadır. Myrdal'a göre, ex-post tasarruflar ex-ante yatırımlardan sapabilir. Ancak, ex-post yatırım ve tasarruf seviyesi dengede olmalıdır. Çünkü uzun dönem açısından toplum gerçek varlıkların birikimi ile tasarruf yapmaktadır. Myrdal'ın bu teorik görüşleri savunurken kümülatif nedensellik prensibini kullandığı görülmektedir. Dinamik süreçte ex-ante beklentileri ex-post hesap dengesi ile sonuçlanmaktadır. Myrdal'a göre bu süreç, bireysel ekonomik kuruluşlarda beklenmedik kazanç ve kayıplara, hatta fiyatların dalgalanmasına neden olacaktır. Yalnızca denge durumunda ex-ante tasarruf ex-ante yatırıma eşit olur ve fiyatların değişmesi için bir baskı söz konusu olmaz (Čaplánová, 2002: 29).

J.M. Keynes ve F. V. Hayek aynı dönemde Myrdal'ın üzerinde çalıştığı sorunlar ile ilgilenmişlerdir. Fakat Myrdal'ın beklentilere vermiş olduğu önem ve rol, onu diğer iktisatçılardan ayırmıştır. Myrdal'ın iktisadi analizlerindeki temel amaçlardan biri, parasal sistemin içine beklentiler kavramını getirmektir. Parasal dengeye etki eden değişikliklerin (miktar olarak) ex-ante olarak kabul edilmesi gerektiğini savunmuştur. Myrdal, bu analiz yöntemini verilen bir zamandaki analiz olarak tanımlamıştır. Myrdal'a göre belli bir dönemin dinamik analizi, ancak nihai fiyatların olduğu gelişimsel eğilimlerden başlanılırsa yapılabilecektir. $\mathrm{Bu}$ eğilimler belirli bir durumda hakim olan beklentiler tarafından belirlenir. $\mathrm{Bu}$ bağlamda ex-ante beklentiler dinamik sürecin hareket gücüdür. Bunun yanında ex-post sonuçlar da önemlidir. Çünkü onlar ex-ante beklentilerin gelecek dönem için başlangıç noktası olmaktadır. 
Myrdal'ın dinamik metodu ex-post dengenin her zaman oluşacağı üzerine inşa edilmiştir. Parasal analiz bakış açısı ile bakıldığında ex-ante ve ex-post durumları arasında meydana gelen değişiklikleri analiz etmek, ex-post dengenin sağlanabilmesi için gereklidir. Myrdal, orijinal beklentilerdeki sapmalardan kaynaklanan ve sapmaların sonucunda ortaya çıkan değişiklikleri önemsediğinden ekonomik analizlerinde bu değişikliklerin nedenlerini de ortaya koymaktadır. Bundaki amaç ex-ante beklentileri ve ex-post beklentilerdeki değişikliklere neden olan unsurları analiz etmektir (Ohlin, 1937: 55).

Myrdal; Knut Wicksell'in kümülâtif sürecini kullanarak parasal denge çalışmalarında toplumun geliri azaldığı takdirde tüketim mallarına olan talebin kaynağı olan toplam satın alma gücündeki azalmanın daha az oranda olacağını belirtmiştir. Bu azalmanın sonucunda, gelirin tasarruf için ayrılan bölümü azalacak ve tasarruflardaki bu azalma sermaye piyasasındaki denge durumunun değişmesine sebebiyet verecektir. $\mathrm{Bu}$ olgu tüketim mallarına olan talep düzeltildiği zaman, fiyatlar seviyesindeki azalmayı sınırlandırarak dolaylı bir etkiye sahip olacaktır. $\mathrm{Bu}$ durum sermaye değerini ve reel yatırımları desteklemektedir. Myrdal bu analizi kullanarak değişmeyen tüketim alışkanlıkları, kredi koşulları kötüye gitse bile parasal dengenin sağlanmasına destek olur sonucuna varmıştır.

$\mathrm{Bu}$ analiz ile azalan bir kümülâtif süreci durduran faktörleri açıklamayı, yatırım ve çıktı düzeyinin artmaya başladığı, ekonomik konjonktürün azalmaya başladığı bir denge noktasını formülize etmeye çalışmıştır. Bu noktada ex-ante, tasarruflar ex-ante yatırımlara eşit olabilir. Myrdal'ın analizinin ağırlık merkezi, devam eden kümülâtif süreçte yatırım ve tasarruflar arasındaki ex-post dengeyi oluşturan faktörleri belirleme çabasıdır (Čaplánová, 2002: 29).

$\mathrm{Bu}$ yüzden Myrdal'a göre parasal denge konsepti, Wicksell'in kümülâtif sürecinin olmadığı durumda, her zaman belirli bir andaki durum ile ilgilenir. Myrdal, parasal dengenin sağlanmasını soyut bir amaç olarak kabul etmemektedir. Myrdal'a göre parasal dengenin oluşum mekanizmasını anlamak, ekonomik konjonktürün etkilerini tamamen ortadan kaldırmasa da azaltmaya katkı sağlayacağı için önem arz etmektedir. Ayrıca Myrdal, parasal dengenin ve diğer amaçların sağlanması için gerekli olan önlemlerin birbiri ile çeliştiğine de dikkat çekmektedir. Bu bağlamda tam istihdam düzeyine gelinebilmesi için yüksek düzeyde toplumsal maliyetlere katlanılmak zorunda olunabileceğini vurgulamıştır (Myrdal,1939). 


\section{Sonuç}

İktisat alanında ünlü olmayı başarmış birinci sınıf iktisatçılar genelde pür teorisyen olarak akademik hayata başlamayı tercih etmişlerdir. Gunnar Myrdal'da aynı tercihle akademik çalışmalarına başlamıştır. 1920'li ve 1930'lu y1llarda Myrdal, İngiltere'deki J.M. Keynes ve Robertson'un fikirleri ile birlikte İsveç'in Stockholm şehrinde modern makroekonominin temellerini atmaya çalışan, geleceği parlak bir gurubun üyeleri arasında yer almıştır. Myrdal'ın parasal denge üzerine yaptığı çalışmalar halen dönemin önemli çalışmaları arasında olduğu göz ardı edilmemelidir.

Karl Gunnar Myrdal'ın ekonomi bilimine olan katkısı binlerce sayfa tutabilecek nitelikte olduğundan tek bir çalışmada toplamak gerçekten güç olmaktadır. 1940 yılından sonra yapmış olduğu çalışmalar Myrdal'a şöhret kazandırmıştır. Bu dönemdeki eserlerinde Amerika'daki zenci toplumu, Nüfus Problemleri, Planlama-Demokrasi, Gelişmişlik ve Azgelişmişlik, Birleşmiş Milletler, Tarım, Ulusal-Uluslar arası Birleşme ve Güney Asya'daki Ekonomik Kalkınma gibi konular üzerinde durmuştur.

Myrdal, ilerlemenin yavaş olduğu, kendi başına ekonomik teknikler sağlamayan, derin bir kavrayış ve hayal gücü gerektiren büyük sorunlara yönelmiştir. Myrdal'ın ilgi alanları coğrafi anlamda da geniştir. Her çeşit ekonomi üzerine çalışmalar yapmıştır. Amerika, Avrupa, Afrika ve Asya kıtalarının birçok ülkesinde seyahat ve çalışma imkânı bulmuştur. Analizleri esnasında işine sıkı sıkıya sarılmış olması ve samimiyeti sayesinde bu ülkelerde yabancılık çekmemiştir. Myrdal'ın iktisadi bakış açımızın gelişmesi konusunda ufkumuzun açılmasına yardımcı olan önemli bir iktisatçı olduğu bir gerçektir.

Myrdal'ın sadece entelektüel katkılarından değil kamusal ilişkilere yaptığı katkılardan da bahsetmek gerekir. Myrdal 1940'lı yıllar boyunca İsveç Parlamentosu'nda Bakanlıkta dahil çeşitli görevlerde bulunmuş ve İsveç ekonomi politikasına yön vermede önemli rolü olmuştur. Vizyonu, cesareti ve diplomatik yeteneği ile bütün dünyada saygınlık kazanmıştır. Myrdal sadece dünyadaki elit kesimden değil ayrıcalıklı olmayan kesimden de ilgi görmüştür. Az gelişmişlik ve kalkınma üzerine çalışmalar yaparak, her zaman alt sınıf olarak görülen kesimin hizmetinde, her zaman onların tarafinda ve her zaman onların koşullarını iyileştirmeye çabalamıştır. Yapmış olduğu hizmetler ve çalışmalar karşılı̆̆ını vermiş ve 1974 yılında F.V.Hayek ile birlikte Nobel Ekonomi Ödülünü kazanmıştır. 
Myrdal ile fikir olarak anlaşamayan, onun görüşlerine katılmayan bilim adamları, Myrdal'ın bilim adamlığını eleştirseler bile, insanlık yönünden örnek bir kişiliğe sahip olduğunu ifade etmekten kaçınmamışlardır.

Sonuç olarak; Karl Gunnar Myrdal sadece iktisadi konularla ilgilenmeyip sosyal konular hakkında da görüş bildiren bir bilim adamı olduğundan, sadece ekonomist olarak değerlendirmek yerine onu sosyal bilimci olarak tanımlamak daha doğru olacaktır. Yaşadığı dönemde yapmış olduğu çalışmalar ve sosyal etkinlikler ile çok az kişiye nasip olan dünya çapında tanınırlığa ulaşmayı başarabilmiştir.

\section{KAYNAKLAR}

Balabkins, N.W. (1988), Gunnar Myrdal (1898-1987). Eastern Economic Journal Vol:XIV, 99-106.

Čaplánová, A. (2002), Gunnar Myrdal. BIATEC - The National Bank of Slovakia, 28-30.

Encyclopædia Britannica. Lars Johan Hierta. Ekim 14, 2011 tarihinde britannica: http://www.britannica.com/EBchecked/topic/265061/LarsJohan-Hierta adresinden alındı.

Kindleberger, C.P. (1987), Gunnar Myrdal, 1898-1987. The Scandinavian Journal of Economics, Vol. 89 , 393-403.

Lindbeck, A. (1992), Nobel Lectures, Economics Sciences 1969-1980. Singapore: World Scientific Publishing Co.

Myrdal, J. (1982), Barndom. Stockholm: Norstedt \& Soners.

Myrdal, K.G. (1939), Monetary Equilibrium. London: W. Hodge Publisher.

Myrdal, K.G. (1975), Against the stream : critical essays on economics. New York: Vintage.

Nobelprize. Alva Reimer Myrda. Ekim 14, 2011 tarihinde nobelprize: http://nobelprize.org/nobel_prizes/peace/laureates/1982/myrdalbio.html adresinden alındı.

Ohlin, B. (1937), Some Notes on the Stockholm Theory of Savings and Investments I. The Economic Journal ,53-69.

Pressman, S. (1999), Fifty Major Economist. London: Routledge.

The New York Times. (1987, May1s 18). Gunnar Myrdal, analyst of race crisis, dies. Ekim 23, 2011 tarihinde http://www.nytimes.com/1987 /05/18/obituaries/gunnar-myrdalanalyst-of-race-crisis-dies.html adresinden alınd. 